\title{
Research Trends in Information Technology Applications in Construction Safety Engineering and Management
}

\begin{abstract}
Through analysis of articles published from 2000 to March 2014 in Automaton in Construction (AUT$\mathrm{CON}$ ), an international research journal published by Elsevier, this paper summarizes the topics of research and the institutions worldwide where research was conducted in construction safety engineering and management. Seventy-one articles published during this time focused on Information Technology (IT) applications in this field were selected for analysis. The underlying research topics and their related IT implementations are discussed, and research trends in allied specialties are identified.
\end{abstract}

Keywords: industrial safety engineering and management, construction technology, building engineering, information technology, automation, international research journal, research trends

\section{Introduction}

Construction is one of the most dangerous industries, causing numerous casualties and property loss in every country around the world. Due to the improvement of production technology in construction, the ever expanding size and complexity of infrastructure projects, and increased expectations in regard to safety performance safety management has become a major challenge to the industry at large. Advances in safety sciences and information technology present an unprecedented opportunity to positively impact the safety performance in construction. There is a compelling need for further innovation to address challenges towards improving the safety performance of the construction industry globally (Kamardeen, 2013).

Information technology-based field data acquisition equipment and tools are instrumental in achieving an ever

Manuscript received January 27, 2014; accepted June 25, 2014

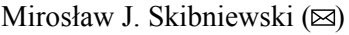

Department of Civil \& Environmental Engineering, University of Maryland, College Park 20742, U.S.

Email:mirek@umd.edu increasing ability to store, retrieve, transmit and manipulate data and information during the conduct of construction projects. Precise and real-time control over workers, equipment, materials, construction methods and work environment are need for safety risk prevention and emergency response. Research on perceived risk based on sensors is conducted to monitor and analyze the safety status on construction sites to prevent workers from being exposed to hazards (Cheng \& Teizer, 2014; Nadar, Awakian \& Khoury, 2013). Robotics and remotely controlled manipulators have been invented and are being improved for high-safety-risk construction activities (Han et al., 2006; Jung et al., 2013). Information systems have been widely discussed for managing massive multisource heterogeneous data generated during construction, so that consistent and timely data can be shared between project participants for effective safety collaboration.

Through the investigation of over 71 articles published in Automation in Construction (AUTCON) in the last 14 years, this paper presents a general review of research related to IT implementations in construction safety.

\section{Overview of automaton in construction international research journal}

AUTCON is an international research journal for the publication of original research articles on the use of Information Technologies in Design, Engineering, Construction Technologies, and Maintenance and Management of Constructed Facilities. The scope of AUTCON is broad, encompassing all stages of the construction life cycle from initial planning and design, through construction of the facility, its operation and maintenance, to the eventual dismantling and recycling of buildings and engineering structures. The following list indicates topics that fall within the journal's purview: (1) Computer-aided design, product modeling, decision support systems, classification and standardization, product data interchange; (2) Computer-aided engineering, process simulation models, graphics; (3) Robotics, metrology, logistics, automated inspection, demolition/remediation; (4) Facilities management, management information systems, intelligent 
control systems.

The readership of AUTCON includes engineers, architects, researchers, systems designers, managers to technologists dealing with the applications of information technologies in design, civil and structural engineering, and construction technologies, including robotics and automated machinery, and maintenance and management control personnel of constructed facilities.

The Thomson Reuters Institute for Scientific Information (ISI) Impact Factor ${ }^{\circledR}$ (IF) of an academic journal is a measure reflecting the average number of citations to recent articles published in the journal. It is frequently used as a proxy for the relative importance of a journal within its field. The IF ${ }^{\circledR}$ values for AUTCON have been generally increasing in over a decade, as shown in Table 1.

Table 1 Automation in Construction IF® from 2002 to 2012

\begin{tabular}{lccc}
\hline Year & Impact factor & Articles & Total cities \\
\hline 2012 & 1.820 & 160 & 1692 \\
2011 & 1.500 & 116 & 1147 \\
2010 & 1.311 & 101 & 996 \\
2009 & 1.372 & 97 & 870 \\
2008 & 1.664 & 93 & 844 \\
2007 & 0.609 & 87 & 391 \\
2006 & 0.792 & 65 & 341 \\
2005 & 0.387 & 63 & 181 \\
2004 & 0.360 & 57 & 148 \\
2003 & 0.320 & 62 & 93 \\
2002 & 0.312 & 52 & 69 \\
\hline
\end{tabular}

\section{Overall research analysis}

From 2000 to March 2014, seventy-one articles on Information Technologies for construction safety management were published or were available in press in AUTCON. As shown in Figure 1, the increased number of publications, especially after 2011, indicates a growing concern for construction safety management and the growing number of proposed implementations of Information Technologies in this important field. Extensive research on construction site monitoring and worker/ equipment safety has been carried out with the use of Radio Frequency Identification (RFID)) technologies, Ultra-wide Band (UwB) and Wireless Networks (WN), Building Information Modeling (BIM) applications, and others.

As shown in Table 2, the 71 analyzed articles can be categorized into three major themes as follows: (1) Sensors and sensor-based systems for construction safety, (2) Robotics and manipulators for construction safety; (3) Information analysis and management along with reporting systems for construction safety.

The top ten countries from which the largest number of published articles originated in the past 14 years are shown in Table 3. China, USA and Korea contributed 61 (85.9\%) of the articles. Considering the massive construction volume in China, a large volume of research on both worker and equipment safety has been conducted involving the use of a variety of IT tools. Among other publications, researchers based in the USA and Korea published five articles on their joint robotic and information systems research aimed at achieving improved construction safety performance (Table4)(Kim \& Elernold, 2008; Kim et al., 2009; Kim \& Russell, 2003; Kim, Seo \& Russell, 2012; Zhang et al., 2013).

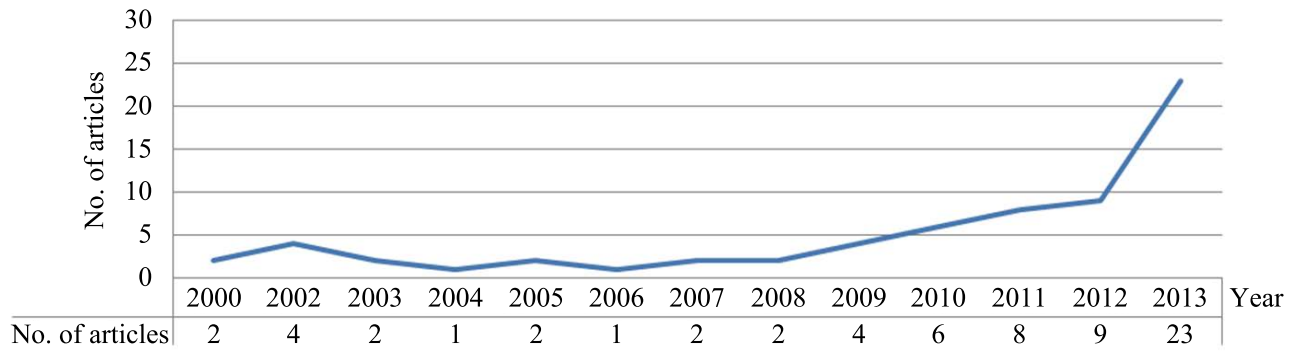

Figure 1. AUTCON publications on IT in construction safety management.

Table 2 Classification of Articles on IT in Construction Safety Published in AUTCON

\begin{tabular}{lcr}
\hline Paper classification & No. of articles & $\begin{array}{r}\text { Proportion to all articles on IT for construction safety in AUTCON } \\
\text { (Jan. 2000-March 2014) }\end{array}$ \\
\hline $\begin{array}{l}\text { Sensors and sensor-based systems for construction safety } \\
\text { Robotics and manipulators for construction safety }\end{array}$ & 17 & 10 \\
$\begin{array}{l}\text { Information analysis and management and reporting systems for } \\
\text { construction safety }\end{array}$ & $44.94 \%$ \\
Total & 71 \\
\hline
\end{tabular}


Table 3 Countries of Origin of AUTCON Articles on IT in Construction Safety (per origin of the corresponding author)

\begin{tabular}{lccc}
\hline Country & No. of articles & $\begin{array}{c}\text { Proportion to all articles on IT for construction safety } \\
\text { in AUTCON (Jan. 2000-March 2014) }\end{array}$ & Rank \\
\hline Greater China (incl. PRC, RoC, & 25 & $35 \%$ & 1 \\
Hong Kong) & 20 & $28 \%$ & 2 \\
USA & 16 & $23 \%$ & 3 \\
South Korea & 3 & $4 \%$ & 4 \\
Canada & 2 & $3 \%$ & 5 \\
Japan & 2 & $3 \%$ & 7 \\
Italy & 1 & $1 \%$ & 7 \\
Spain & 1 & $1 \%$ & 7 \\
Netherland & 1 & $1 \%$ & \\
Slovenia & & & \\
\hline
\end{tabular}

Table 4 Research Institutions in IT for Construction Safety Represented by AUTCON Corresponding Authors

\begin{tabular}{lccc}
\hline Rank & Country & Research institution & Number of articles in AUTCON \\
\hline 1 & (1) Huazhong University of Science \& Technology & 6 \\
& (2) Tsinghua University & 4 \\
& (3) The Hong Kong Polytechnic University & 3 \\
& (3) National Taiwan University of Science and Technology & (1) Georgia Institute of Technology & 12 \\
& (2) University of Michigan & 2 & 2 \\
& (2) University of Central Florida & (1) Korea University & 4 \\
& (1) Yonsei University & 4 \\
\end{tabular}

Table 5 AUTCON Corresponding Authors of Papers on IT-based Construction Safety Management

\begin{tabular}{|c|c|c|c|c|}
\hline Corresponding author & Research institution & $\begin{array}{c}\text { No. of articles in } \\
\text { AUTCON }\end{array}$ & $\begin{array}{c}\text { Proportion to all articles on IT for } \\
\text { construction safety in AUTCON } \\
\text { (Jan. 2000-March 2014) }\end{array}$ & Rank \\
\hline Jochen Teizer & $\begin{array}{l}\text { RAPIDS Laboratory (formerly at Georgia } \\
\text { Institute of Technology) }\end{array}$ & 12 & $17 \%$ & 1 \\
\hline Ghang Lee & Yonsei University & 4 & $6 \%$ & 2 \\
\hline Lie-yun Ding & $\begin{array}{c}\text { Huazhong University of Science and } \\
\text { Technology }\end{array}$ & 2 & $3 \%$ & 3 \\
\hline Cheng Zhou & $\begin{array}{c}\text { Huazhong University of Science and } \\
\text { Technology }\end{array}$ & 2 & $3 \%$ & 3 \\
\hline Heng Li & The Hong Kong Polytechnic University & 2 & $3 \%$ & 3 \\
\hline Zhen-zhong Hu & Tsinghua University & 2 & $3 \%$ & 3 \\
\hline Wei-wei Wu & Southeast University & 2 & $3 \%$ & 3 \\
\hline Min-yuan Cheng & $\begin{array}{c}\text { National Taiwan University of Science and } \\
\text { Technology }\end{array}$ & 2 & $3 \%$ & 3 \\
\hline Sung-Keun Kim & Korea Institute of Construction Technology & 2 & $3 \%$ & 3 \\
\hline
\end{tabular}




\section{Classification of research on IT-based con- struction safety management}

\subsection{Sensors and sensor-based systems for safety}

There have been 17 articles published in AUTCON on sensors and sensor-based system in the past 14 years, as shown in Table 6 and Figure 2. Eleven research institutions from 7 countries and 3 continents have been active in this research topic. Half of those articles are focused on the use of RFID, a type of automatic identification technologies in which radio frequencies are used to capture and transmit data from a tag, or transponder.

1) RFID sensors. The major applications of RFID sen- sors are the developments of safety early warning systems that could inform workers of potential safety risks on site. As shown in Figure 3, with real-time visible and traceable information, equipment collision accidents can be prevented (Chae \&Yoshida, 2010), if workers-on-foot and equipment operators have been warned or alerted when one gets too close to the equipment (Teizer et al., 2010). Besides conflict zone detection and vertical construction resource tracking (Costin, Pradhananga \& Teizer, 2012) a three-dimensional location-sensing algorithms have been developed to analyze the possible 3D locations of objects based on RFID sensor-generated information (Ko, 2010). However, the signal attenuation effect caused by the surrounding environment was not taken into consideration in these studies.

Table 6 AUTCON Corresponding Authors on Sensor and Sensor-based Systems for Construction Safety Management

\begin{tabular}{|c|c|c|c|c|c|}
\hline Research institution & $\begin{array}{l}\text { Total No. of articles } \\
\text { from Institution }\end{array}$ & Corresponding author & $\begin{array}{l}\text { No. of articles by } \\
\text { corresponding author }\end{array}$ & $\begin{array}{c}\text { Proportion to robotics and } \\
\text { manipulators articles on IT for } \\
\text { construction safety in AUTCON } \\
\text { (Jan. 2000-March 2014) }\end{array}$ & Rank \\
\hline Georgia Institute of Technology & 5 & Jochen Teizer & 5 & $29 \%$ & 1 \\
\hline $\begin{array}{l}\text { Università Politecnica delle } \\
\text { Marche }\end{array}$ & 2 & Alessandro Carbonari & 2 & $12 \%$ & 2 \\
\hline Southeast University & 2 & Weiwei Wu & 2 & $12 \%$ & 2 \\
\hline Shanghai Jiao Tong University & 1 & Yanming Li & 1 & $6 \%$ & 4 \\
\hline University of Calgary & 1 & Farnaz Sadeghpour & 1 & $6 \%$ & 4 \\
\hline Korea University & 1 & Hunhee Cho & 1 & $6 \%$ & 4 \\
\hline Lamar University & 1 & Seokyon Hwang & 1 & $6 \%$ & 4 \\
\hline University Carlos III of Madrid & 1 & Mohamed Abderrahim & 1 & $6 \%$ & 4 \\
\hline Loughborough University & 1 & Weiwei Wu & 1 & $6 \%$ & 4 \\
\hline $\begin{array}{l}\text { Kajima Technical Research } \\
\text { Institute }\end{array}$ & 1 & Soungho Chae & 1 & $6 \%$ & 4 \\
\hline Yonsei University & 1 & Ghang Lee & 1 & $6 \%$ & 4 \\
\hline $\begin{array}{l}\text { National Pingtung University of } \\
\text { Science and Technology }\end{array}$ & 1 & Chien-Ho Ko & 1 & $6 \%$ & 4 \\
\hline
\end{tabular}

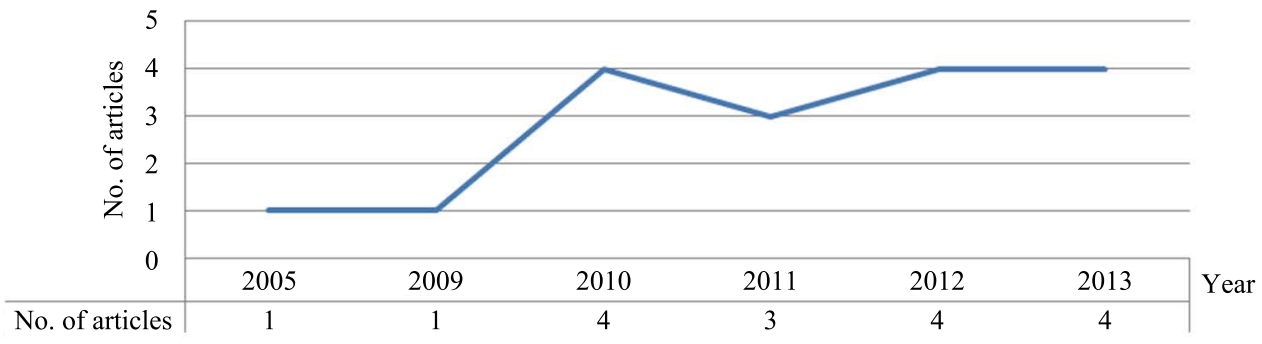

Figure 2. Articles published in AUTCON between 2005 and 2013 on sensors and sensor-based systems for construction safety. 
As ZigBee technology provides a reliable, low cost and easy to deploy wireless sensor network solution, researchers have explored the feasibility to use Zigbee RFID sensors networks to prevent workers from being struck by falling objects, and to track near-miss accidents by tracking the allocation of workers, equipment and materials (Wu et al., 2013; Wu et al., 2010). Although the field trial in a warehouse indicated the tracking signal would be weakened when emitters are obstructed, this problem can be overcome with a careful layout. Research on monitoring interference between teams at work can lead to the ability to alert project personnel of the occurrence of physical interference of work crews and to identifying and predicting problematic work conduct by workers (Naticchia, Vaccarini \& Carbonari, 2013). The RFID tags can be attached to safety gear such as personal protective equipment (PPE) to support the compliance checking process (Kelm et al., 2013) as shown in Figure 4. In an event of non-compliance with safety-mandated behavior, recording of the presence of workers on-site and checking whether any member of a team accessed an unauthorized area where interference with other work teams could take place would be possible. Nonetheless, a number of remaining problems need to be solved before such systems can be implemented in industry practice. Besides the concerns for capturing re- al-time information of workers on site, automatic, real time zoning updates of construction sites for safety, and registering potential risks using RFID tags are still unresolved issues. Technical and financial challenges with RFID-enabled safety precaution systems need to be further explored ( $\mathrm{Lu}$, Huang, \& Li, 2011).

2) Automated tracking based on ultra-wideband sensor. Emerging wireless remote sensing technologies offer significant potential to advance the management of construction processes by providing real-time access to the locations of workers, materials, and equipment. Depending on site constraints and on the scope of management activities, past research has shown that predicting potential risk situations calls for real-time intelligent site monitoring and the ability to react when the level of risk increases. To date, the most promising tracking technology are RFID, Global Positioning System (GPS), Wireless Local Area Networks (WLAN), UwB and Indoor GPS, for their ability to cover a wide range of accuracy values and yard areas (Carbonari, Giretti \& Naticchia, 2011). UwB is a radio-based technology that may be used at a very low energy level for short-range, high-bandwidth communications using a large portion of the radio spectrum. Unfortunately, little is known regarding the accuracy, reliability, and practical benefits of this emerging tech-

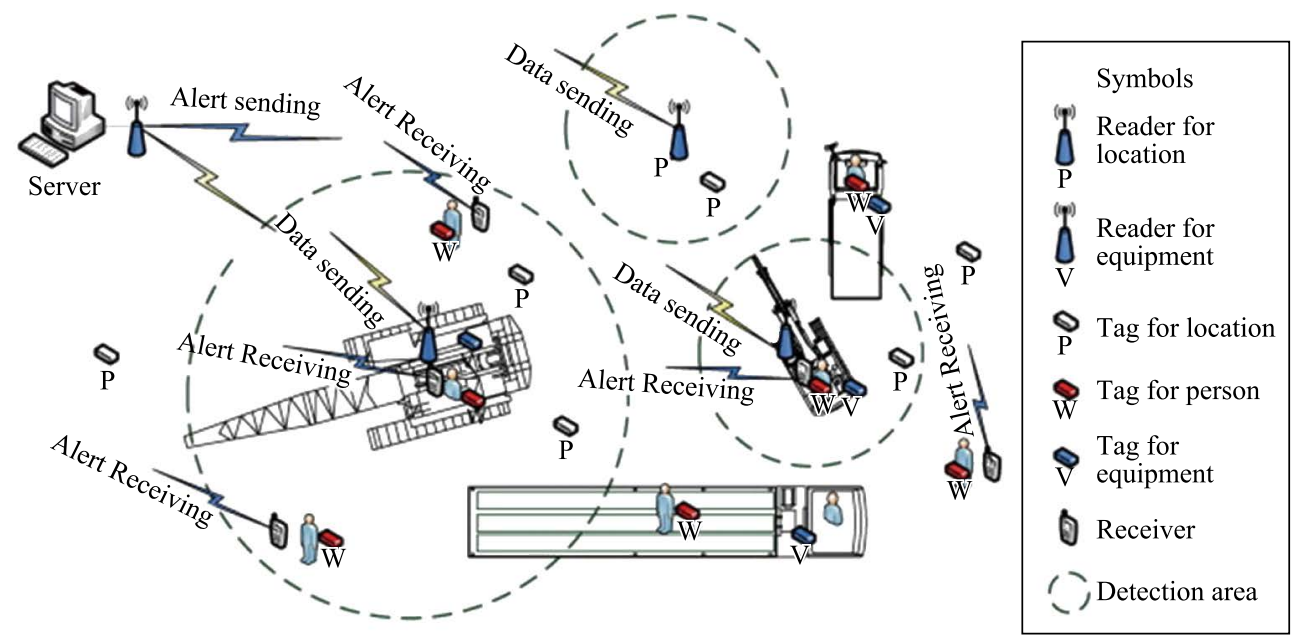

Figure 3. Location of tags and divided excavation area (Chae \&Yoshida, 2010).
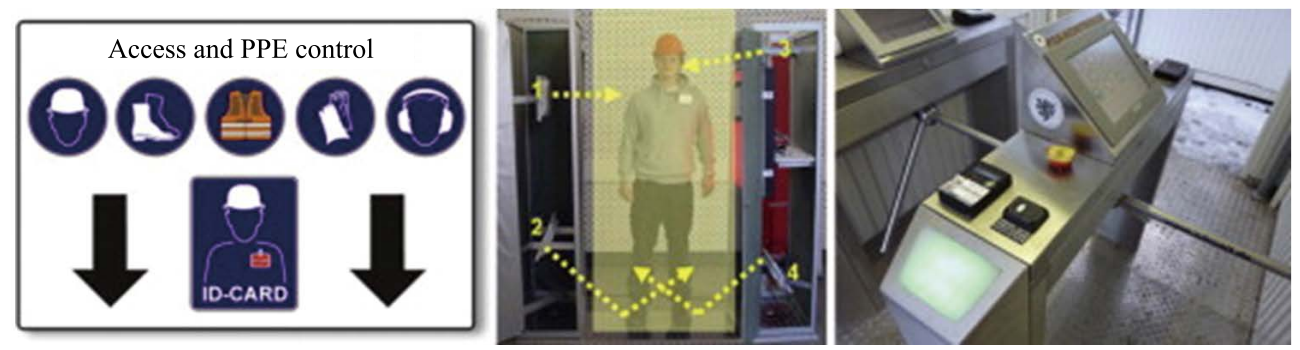

Figure 4. PPE using RFID tags to support the compliance checking process (Kelm et al., 2013). 
nology, effectively impeding widespread adoption (Cheng et al., 2011). In face of that, efforts are made to evaluate the performance, including tracking accuracy, location error rates of a commercially available UwB systems for real-time, mobile resource location tracking in challenging construction environments (e.g. resource rich, spatially complex, cluttered with metallic objects causing interference). Sufficient accuracy for practical implementation was achieved in large open space construction environments (Cheng et al., 2011), see Figure 5.

For outdoor automated applications of dynamic tracking based on an UwB technology, a prototype system for proactive safety management and real-time signaling of potential overhead hazards was developed. The system was conceived to act without the need to tag workers and other resources. Distances are in fact measured through IR and ultrasonic sensors. Its results suggest further system enhancement geared towards use cases involving dynamically changing hazardous areas (Carbonari, Giretti \& Naticchia, 2011). A method for preventing equipment collision by helping equipment operators improved their situational awareness while operating equipment on site was also reported. Although this study was only conducted at a laboratory scale, the reported research examined technical feasibility and expected benefits of integrating collision-prevention approaches with UwB technology for preventing equipment collisions (Hwang, 2012).

For indoor scenarios, another study aimed at assessing performance of UwB tracking systems in a static mode under a set of conditions that can commonly occur on construction sites. The study measured the extent of the impact of variables that represent seven conditions that would have a negative impact on the accuracy of the location estimation data provided by UwB (Maalek \& Sadeghpour, 2013).The study reported an evaluation of the static and dynamic performance of a commercially-available UwB tracking system in free space and under realistic construction environment scenario. The results of these tests were in agreement with the manufacturer specifications for the UwB systems tested in outdoor environment (Saidi et al., 2011).

3) Other sensor-based research. For a construction equipment operator encountering blind spots, a navigation system that provides $3 \mathrm{D}$ information in real time about a building and its surroundings, and the position of the object being lifted have been developed using laser and encoder sensors (Lee et al., 2012). For on-site workers, distance measurement with ultrasonic and infrared sensors have been developed to reduce the rate of fatal accidents on construction sites susceptible to fall accidents (Lee et al., 2009). With positioning and personal ID sensors in the worker's hardhat, actual location of each worker is compared and verified with a database containing the tasks and processes being performed on site (Abderrahim et al., 2005; Li \& Liu, 2012).

\subsection{Robotics and manipulators for safety}

The construction industry has been a challenging field for the application of robotic technologies. However, the construction industry involves dangerous environmental characteristics which cause poor working conditions for construction laborers (Skibniewski, 1988). Replacing human laborers with robotic systems has many advantages such as increased quality, productivity and safety. Due to the complexity of research on robotics and manipulators, the articles focused on this category of topics are relatively fewer in the last decade than the other categories analyzed in this paper, see Figure 6. Earlier volumes of AUTCON dating back to 1992 feature more research activities in this area (Dolinsek \& Duhovnik, 1998; Hussien \& McLaren, 1992; Hussien \& McLaren, 1993; Taher et al., 1994).

1) Human-machine interaction for automated construction. Collaboration between a robot and a human worker during construction may be highly beneficial in achieving improved productivity and quality levels. In extreme project environments, construction robots may be the only equipment suitable for work performance, particularly in chemically or radioactively contaminated construction environments. For example, an automated excavation system, incorporating
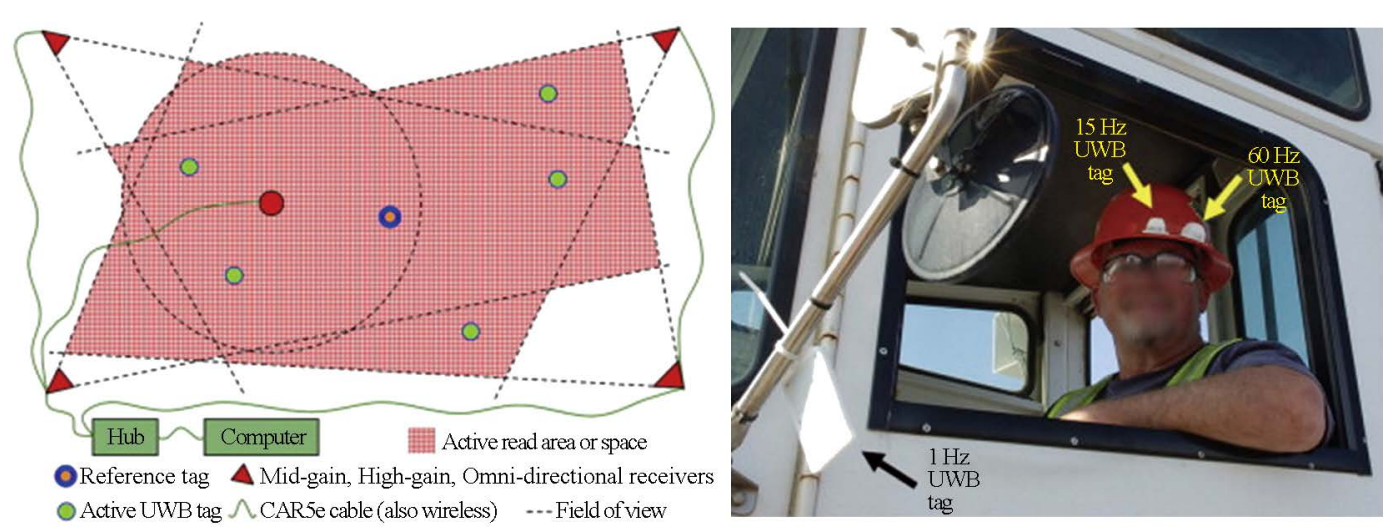

Figure 5. Triangulation of UwB tags using UwB receivers that overlap the coverage area/space inside a lay-down yard (Cheng et al., 2011). 
the intelligence of a construction planner and a skillful operator, has been developed to generate an optimal excavation plan based on 3D models of the structure being constructed in a given work environment and of the excavator (Seo et al., 2011). Other studies have focused on automated systems for lifting heavy structural components, transportation and assembly aiming at precise control of the work being performed. To cope with the lack of skilled workforce and with increased levels of hazards for human workers, a genetic algorithm-based repetitive tasks simulation (CARTS) model has been developed for planning steel erection in high-rise building construction. The results have shown the model's capacity and justified its application to generic types of robotic construction systems (Yoo et al., 2012).

Another application in steel construction focuses on a robotic performance of steel beam assembly. The robotic steel beam assembly system consists of a robotic bolting device that performs the main function for the beam assembly work and a robotic transport mechanism that transports the robotic bolting device to target bolting positions around a building under construction (Kelm et al., 2013; Wu et al., 2013). Through field tests of the prototype and its application to a building construction project, the study shows the potential to replace laborers with a robotic system for steel beam assembly during high-rise building construction. Other research on vertical transportation in lifting construction materials to elevated locations where the material is to be installed, as an alternative to traditional tower cranes, has also been reported in the form of a robotic tower-crane system. Additionally, the feasibility of laser-technology-based lift-path tracking for a robotic tower-crane has been examined. Instead of traveling only through preplanned paths, the proposed robotic tower-crane has shown the feasibility under various jobsite conditions (Lee et al., 2009). Miscellaneous research on lifting machine components such as tower-crane hook blocks (Lee et al., 2012) and hydraulic telescopic handlers (Cinkelj et al., 2010) has also been published.

2) Evaluation of current robotics and manipulators. Pipe laying work involves the work of human laborers in trenches, one of the least safe construction tasks (Table 7). Two papers published in AUTCON over the last decade discuss existing construction machinery for concrete pipe laying. One paper evaluates performance of the hume concrete pipe manipulator (HCPM) commissioned by the Korea Ministry of Construction and Transportation. Based on the analysis of HCPM's overall work performance on a construction site, $65 \%$ in productivity improvement, and $33 \%$ in cost savings has been reported (Kim et al., 2009). Additionally, comparisons have been described between researches teams in Korea and in the U.S. focused on installing large concrete pipe tele-robotically. The paper compares how the two research teams have solved some of the most unique technical problems in these operations, and presents the lessons learned during the field tests without human personnel in the trench. Both prototypes reported improvements in productivity and unit cost (Kim \& Elernold, 2008).

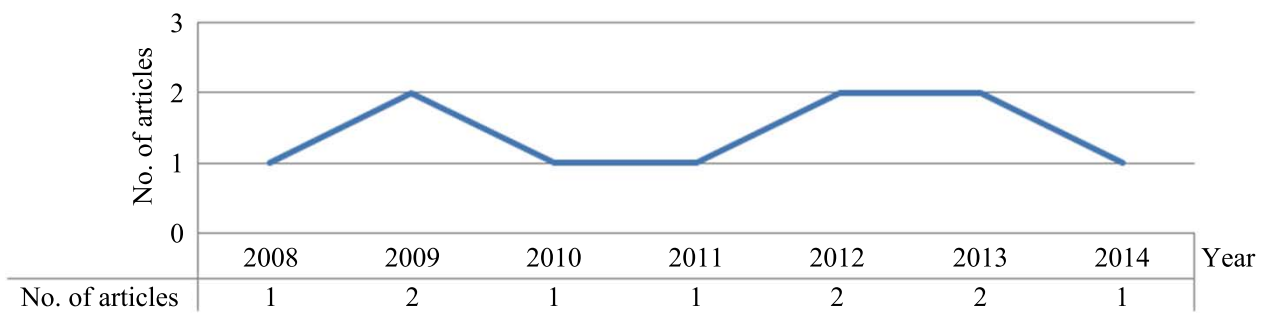

Figure 6. AUTCON articles on robotics and manipulators for construction safety.

Table 7 Leading Institutions and Corresponding Authors on Robotics and Manipulators for Construction Safety Management

\begin{tabular}{lcccc}
\hline Research institution & $\begin{array}{c}\text { Total No. of } \\
\text { articles from } \\
\text { Institution }\end{array}$ & $\begin{array}{c}\text { Corresponding } \\
\text { author }\end{array}$ & $\begin{array}{c}\text { No. of articles by } \\
\text { corresponding author }\end{array}$ & $\begin{array}{c}\text { Proportion to robotics and } \\
\text { manipulators articles on IT for } \\
\text { construction safety articles in } \\
\text { AUTCON (Jan. 2000-March 2014) }\end{array}$ \\
\hline Yonsei University & 3 & Ghang Lee & 3 & $30 \%$ \\
Korea University & 3 & $\begin{array}{c}\text { Daehie Hong } \\
\text { Hunhee Cho }\end{array}$ & 2 & $30 \%$ \\
Korea Institute of Construction Technology & 1 & Kyoon-Tai Kim & 1 & 1 \\
University of Ljubljana & 1 & Justin Činkelj & 1 & $10 \%$ \\
Inha University & 1 & Young S. Kim & 1 & 3 \\
Seoul National University of Science \& & 1 & Sung-Keun Kim & 1 & $10 \%$ \\
Technology & & & 3 & $10 \%$ \\
\hline
\end{tabular}


Based on publications in AUTCON alone, it appears that Korea has had the most active research program in this field over the last decade, as it has contributed $90 \%$ of all articles on robotics and manipulators for construction safety management. A total of 6 research institutions from 2 countries and 2 continents have been active in this field.

4.3 Information analysis, management and reporting systems for safety

As shown in Figure 7, research papers related to BIM application to improving construction safety, laser scan status capture and early warning system were published in increas- ing numbers in 2013 due to the publication of a special issue based on expanded, updated and refereed papers presented at Australasian Conference on Innovative Technologies in Construction (ITC2012) in June 2012.

As shown in Table 8, over 20 research institutions from 6 countries and 3 continents were involved in construction safety research focused on the implementation of IT tools. These research institutions were mainly based in China and the USA, and researchers from these two countries contribute the most active research program in this field over the last decade.

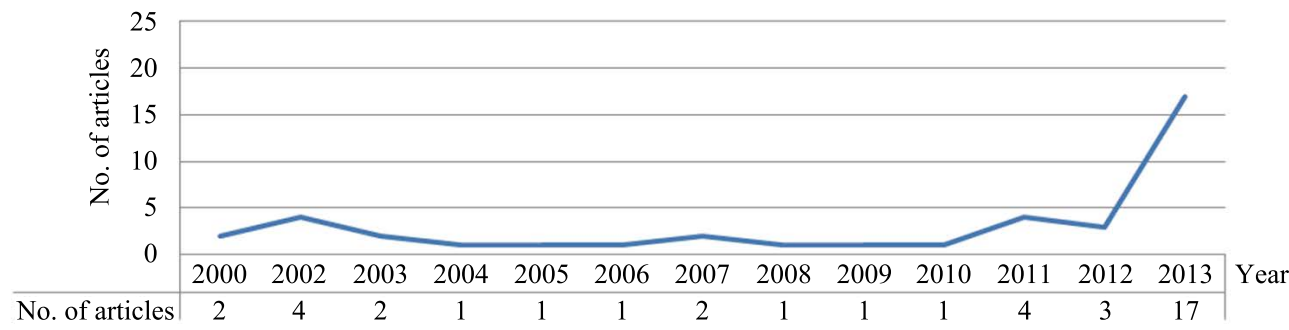

Figure 7. AUTCON articles on information analysis and reporting systems for construction safety.

Table 8 Research Institutions and Corresponding Authors on Information Analysis and Reporting Systems for Construction Safety Management

\begin{tabular}{|c|c|c|c|c|c|}
\hline Research institution & $\begin{array}{l}\text { Total No. of } \\
\text { articles from } \\
\text { institution }\end{array}$ & $\begin{array}{l}\text { Corresponding } \\
\text { author }\end{array}$ & $\begin{array}{l}\text { No. of articles by } \\
\text { corresponding } \\
\text { author }\end{array}$ & $\begin{array}{l}\text { Proportion of robotics and manipulators articles } \\
\text { by given corresponding author to all robotics and } \\
\text { manipulators for construction safety articles in } \\
\text { AUTCON (Jan. 2000-March 2014) }\end{array}$ & Rank \\
\hline $\begin{array}{l}\text { Georgia Institute of Technology RAP- } \\
\text { IDS Laboratory (formerly) }\end{array}$ & 7 & Jochen Teizer & 7 & $16 \%$ & 1 \\
\hline \multirow{4}{*}{$\begin{array}{l}\text { Huazhong University of Science \& } \\
\text { Technology }\end{array}$} & \multirow[t]{4}{*}{6} & Lieyun Ding & 2 & \multirow[t]{4}{*}{$14 \%$} & \multirow[t]{4}{*}{2} \\
\hline & & Cheng Zhou & 2 & & \\
\hline & & Hanbin Luo & 1 & & \\
\hline & & Hong Liang Yu & 1 & & \\
\hline \multirow[t]{3}{*}{ Tsinghua University } & \multirow[t]{3}{*}{4} & Zhenzhong $\mathrm{Hu}$ & 2 & \multirow[t]{3}{*}{$9 \%$} & \multirow[t]{3}{*}{3} \\
\hline & & Dongping Fang & 1 & & \\
\hline & & Hong Ling Guo & 1 & & \\
\hline \multirow[t]{2}{*}{ Chung-Ang University } & \multirow[t]{2}{*}{3} & Chan Sik Park & 2 & \multirow[t]{2}{*}{$7 \%$} & \multirow[t]{2}{*}{4} \\
\hline & & Changwan Kim & 1 & & \\
\hline \multirow{2}{*}{$\begin{array}{l}\text { The Hong Kong Polytechnic Universi- } \\
\text { ty }\end{array}$} & \multirow[t]{2}{*}{3} & Heng Li & 2 & \multirow[t]{2}{*}{$7 \%$} & \multirow[t]{2}{*}{4} \\
\hline & & Greg Chan & 1 & & \\
\hline \multirow{2}{*}{$\begin{array}{l}\text { National Taiwan University of Science } \\
\text { and Technology }\end{array}$} & \multirow[t]{2}{*}{3} & Min-Yuan Cheng & 2 & \multirow[t]{2}{*}{$7 \%$} & \multirow[t]{2}{*}{4} \\
\hline & & Yo-Ming Hsieh & 1 & & \\
\hline \multirow[t]{2}{*}{ University of Michigan } & \multirow[t]{2}{*}{2} & SangHyun Lee & 1 & \multirow[t]{2}{*}{$5 \%$} & \multirow[t]{2}{*}{7} \\
\hline & & Vineet R. Kamat & 1 & & \\
\hline \multirow[t]{2}{*}{ University of Central Florida } & \multirow[t]{2}{*}{2} & $\begin{array}{l}\text { Ahmed Khalafal- } \\
\text { lah }\end{array}$ & 1 & \multirow[t]{2}{*}{$5 \%$} & \multirow[t]{2}{*}{7} \\
\hline & & Amr A Oloufa & 1 & & \\
\hline \multirow[t]{2}{*}{ National Chiao Tung University } & \multirow[t]{2}{*}{2} & Ren-Jye Dzeng & 1 & \multirow[t]{2}{*}{$5 \%$} & \multirow[t]{2}{*}{7} \\
\hline & & Wei-Chih Wang & 1 & & \\
\hline
\end{tabular}




\begin{tabular}{|c|c|c|c|c|c|}
\hline Research institution & $\begin{array}{l}\text { Total No. of } \\
\text { articles from } \\
\text { institution }\end{array}$ & $\begin{array}{l}\text { Corresponding } \\
\text { author }\end{array}$ & $\begin{array}{l}\text { No. of articles by } \\
\text { corresponding } \\
\text { author }\end{array}$ & $\begin{array}{l}\text { Proportion of robotics and manipulators articles } \\
\text { by given corresponding author to all robotics and } \\
\text { manipulators for construction safety articles in } \\
\text { AUTCON (Jan. 2000-March 2014) }\end{array}$ & Rank \\
\hline City University of Hong Kong & 1 & Brian Wilkins & 1 & $2 \%$ & 10 \\
\hline Tun-Nan Institute of Technology & 1 & Jia-chong Du & 1 & $2 \%$ & 10 \\
\hline $\begin{array}{l}\text { Korea Institute of Construction Tech- } \\
\text { nology }\end{array}$ & 1 & Sung-Keun Kim & 1 & $2 \%$ & 10 \\
\hline Gyeongsang National University & 1 & LeenSeok Kang & 1 & $2 \%$ & 10 \\
\hline $\begin{array}{l}\text { University of British Columbia|Okana- } \\
\text { gan }\end{array}$ & 1 & Kasun N. Hewage & 1 & $2 \%$ & 10 \\
\hline University of Waterloo & 1 & Frederic Bosche & 1 & $2 \%$ & 10 \\
\hline University of Hong Kong & 1 & $\begin{array}{l}\text { B.H.W Hadikusu- } \\
\text { mo }\end{array}$ & 1 & $2 \%$ & 10 \\
\hline University of Wisconsin & 1 & Yong-Kwon Cho & 1 & $2 \%$ & 10 \\
\hline Hazama Corp. & 1 & Yoshio Maruyama & 1 & $2 \%$ & 10 \\
\hline Virginia Tech & 1 & $\begin{array}{l}\text { Mani Golparvar- } \\
\text { Fard }\end{array}$ & 1 & $2 \%$ & 10 \\
\hline The University of Texas at Austin & 1 & Soon-Wook Kwon & 1 & $2 \%$ & 10 \\
\hline Hanyang University & 1 & Jongwon Seo & 1 & $2 \%$ & 10 \\
\hline
\end{tabular}

4.3.1 BIM-based spatial-schedule conflict analysis and structural safety

Schedule-workspace interference is generated when workspaces that share parallel schedules and are physically adjacent to one another exist simultaneously. When workspace interference is generated, securing work performance safety is difficult and constructability can deteriorate due to increased collision risk between resources. In 2003, a study related to situation awareness of equipment operators has been done using Differential Global Positioning System (DGPS), wireless technologies. The researchers developed and implemented technologies for vehicle tracking, and collision detection to sense their environment with the objective of increasing safety and improving productivity on construction sites (Oloufa, Ikeda \& Oda, 2003). In 2014, based on BIM, an active simulation system has been developed after constructing a genetic algorithm (GA) process for an alternative schedule that minimizes the simultaneous interference level of the schedule-workspace (Moon et al., 2014). The results show how a simple visualization-oriented BIM system can be extended to an active schedule management system equipped with decision-making functions of workspace analysis.

Based on new developments in BIM, four-dimensional (4D) technology, time-dependent structural analysis and collision detection, a 4D structural information model was presented as a proposed solution to spatial-scheduling conflicts and safety hazards during construction (Hu \& Zhang, 2011). The 4D-GCPSU 2009 system was developed to achieve the information-based integrated construction safety management environment, e.g., time-based stress/strain analysis of structures under construction, schedule, resource and cost conflict analysis, as well as a dynamic collision detection warning amongst temporary facilities and the main structure's components during erection (Hu \& Zhang, 2011).

Using a combination of augmented reality (AR), location tracking, and game technologies, Korean researchers proposed a framework for BIM-based safety management and visualization (Park \& Kim, 2013), and a rule-based checking system to include automated hazard identification and abatement during the construction planning phase (Zhang et al., 2013).

\subsubsection{Metro construction safety early warning systems}

As meaningful improvement in safety performance in metro construction is difficult, time-consuming and unreliable due to the lack of safety performance information and of experienced safety managers. Safety management in large-scale projects requires understanding and addressing technical and managerial complexities involved in the design and implementation of these projects (Ding \& Li, 2013).

In pre-construction phrase, estimations of safety risk level and distribution for metro construction are made by very limited number of experts. Instant risk identification of risk management of metro and underground construction can be accomplished using an safety risk identification system (SRIS) based on construction drawings and risk identification rules to identify potential safety hazards, identify risks automatically and provide a basis for early warning and risk control (Ding et al., 2012).

In construction phrase, a web-based system was developed for safety risk early warning in urban metro construc- 
tion and validated on several projects in China. A hybrid data fusion model based on multisource information (monitoring measurements, calculated predictions, and visual inspections) was employed to automatically imitate human experts giving safety risk assessment and early warning (Ding \& Zhou, 2013). To predict safety conditions on the construction site based on a multidimensional data model, a safety-oriented geotechnical instrumentation data warehouse was established integrating all the data from heterogeneous sources for quick retrieval of information on site and for further analysis of ground settlement (Ma, Luo \& Chen, 2013). A predictive control system for air chamber pressure in slurry shield tunneling was introduced to improve stability of excavation face (Zhou, Ding \& He, 2013).

In order to improve web-based tools for construction safety management, "internet of things" (IoT) technology was introduced to create a sensor-saturated networked environment on a construction site, see Figure 8 . With the seamless integration of a fiber bragg grating (FBG) sensor systems and a RFID-based labor tracking systems, a comprehensive metro construction safety control system and devices were initially developed to overcome the risk control lags in the in construction process and verified through an application at the crossing passage in the Yangtze Riverbed Metro Tunnel project (Ding et al., 2013). In addition, the research team developed an original virtualized safety risk spatial-temporal coupling system to break through bottleneck of relying on single warning index for metro construction management based on BIM technology. So safety status of related components could be continuously visualized as conditions changed and potential safety risks evolved (Zhou, Ding \& Chen, 2013).

4.3.3 Laser scan and range point cloud for spatial information acquisition

For point cloud data acquisition and processing, accurate and rapid assessment of the as-built status on a construction site provides the opportunity to understand the current performance of a project. Rapid project assessment further identifies discrepancies between the as-built and as-planned progress, and facilitates decision making on the necessary remedial actions. To improve error-prone and time-consuming ways of conventional visual observations and surveying, research on automatic recognition of as-built condition and visualization of construction progress was conducted (Golparvar-Fard et al., 2011). For better accuracy and efficient data acquisition, performance evaluation of an unmanned aerial vehicle (UAV) for mobile, rapid and autonomous acquisition of three-dimensional (3D) mapping data was carried out. A performance model for estimating the position error was developed and tested in several realistic construction scenarios (Siebert \& Teizer, 2014), as shown in Figure 9. Efforts are made for robust automated recognition/ retrieval of 3D CAD objects in range point clouds in the Architectural/Engineering/Construction \& Facility Management
(AEC-FM) context (Bosche \& Haas, 2008). However, more questions remain to be addressed and additional research is required for algorithms that automatically extract conventional or parametric CAD objects from laser scanners or image-based point cloud models (Golparvar-Fard et al., 2011). In view of this, a new approach was proposed and tested in laboratory experiments.

A 3D laser scanning of the earth's surface and a global positioning system (GPS) to obtain global geographic coordinates was presented for applications in construction projects through acquisition of landslide data and computing of earthwork volumes. Although thus calculated volumes may not be accurate when compared to conventional methods such as triangulation, field and office durations of operations could be reduced (Du \& Teng, 2007).

As the visibility of personnel and vital materials on construction sites are essential to equipment operators, the blind spots of construction equipment should be carefully identified as part of the instruction routine in operator training. An automated blind spot detection tool was presented that determines the equipment blind spots rapidly and in 3D through analysis the point cloud data from a laser scan inside the equipment cab (Teizer, Allread \& Mantripragada, 2010), see Figure 10. Other approaches to compute blind spot in a fast and efficient way using point cloud data of equipment were presented and validated against synthetic "noisy" point clouds, robustness and accuracy (Ray \& Teizer, 2013).

\section{Conclusions and future research}

\subsection{Conclusions}

Information technology has been applied in a wide array of applications to provide solutions to construction safety problems. Efforts made by researchers to monitor performance of workers, equipment and construction environment, to replace human operations with robots and to collaborate among themselves are vital in creating a safe-working environment and to reduce casualties.

Research on sensors for fast and accurate tracking of construction resources for construction safety management was actively pursued in the past 14 years. Strategy for deployment of RFID sensor networks and their performance were among the most frequently discussed topics. A variety of technologies offered diverse capabilities for enhancing the overall safety performance. ZigBee, UwB, GPS, WLAN, and $3 \mathrm{D}$ virtualization technologies complement one another to increase reliability and timeliness of sensing and tracking locations in indoor or outdoor scenarios. Thus, it was worthwhile to examine the potential of hybrid systems comprising multiple technologies (Hwang, 2012). Research in choosing and combining these technologies for most cost effective applications has been expected. For fast as-built status determination and compliance analysis, 3D laser scan technology was determined to be an efficient first step for spatial infor- 


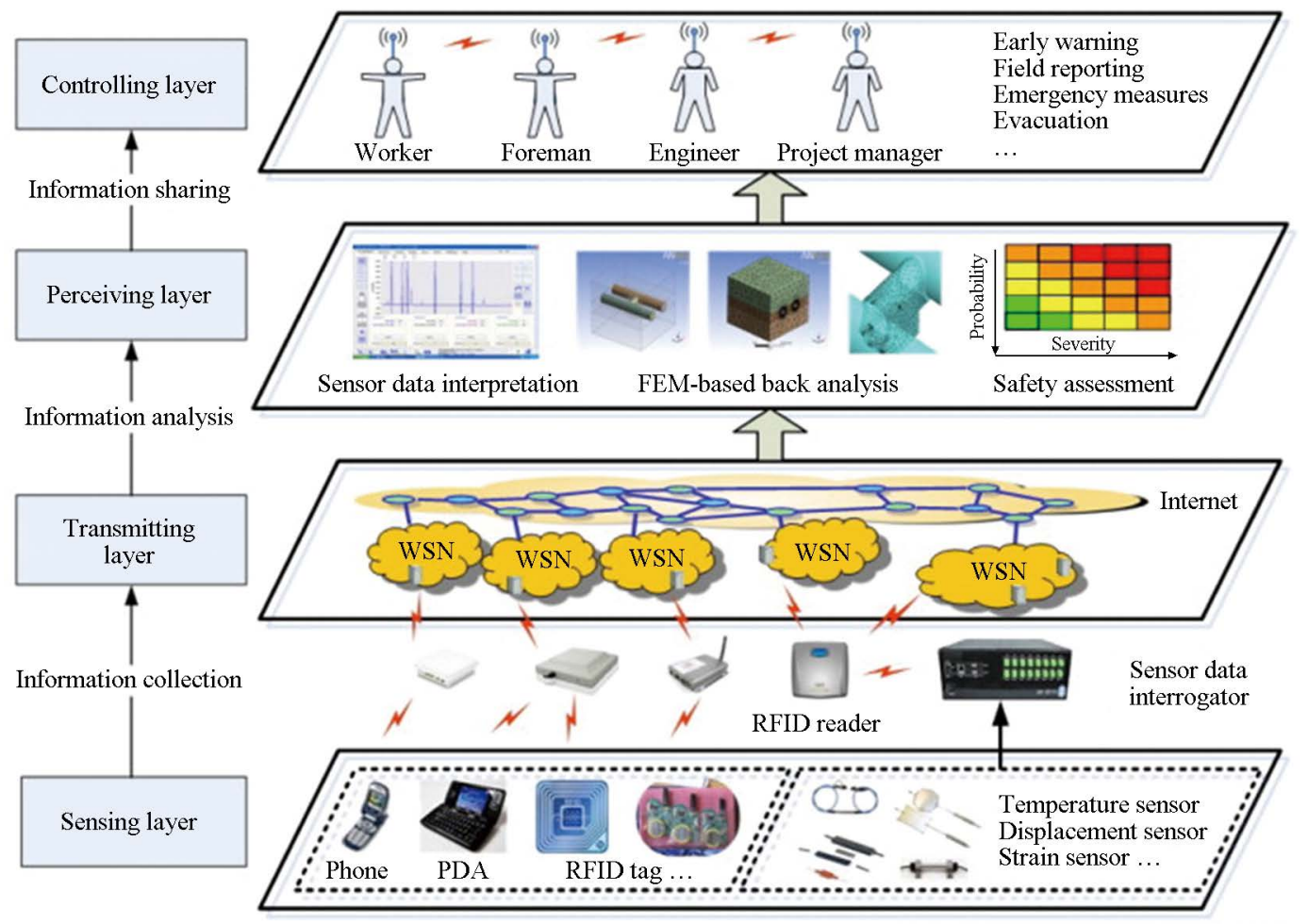

a)

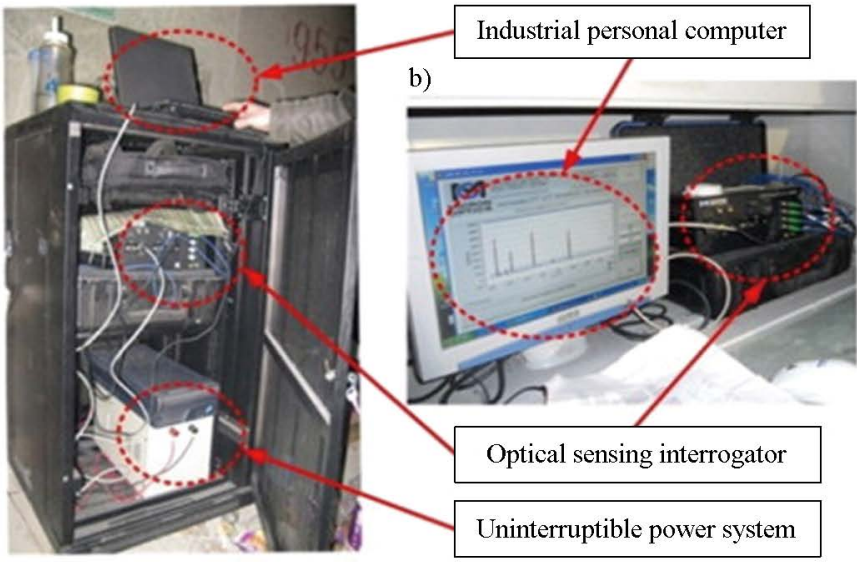

c)

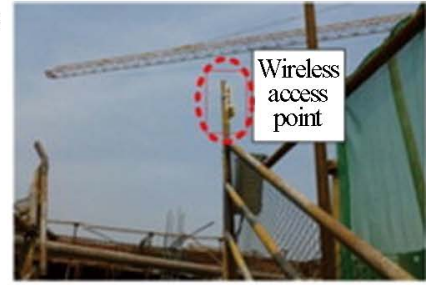

d)

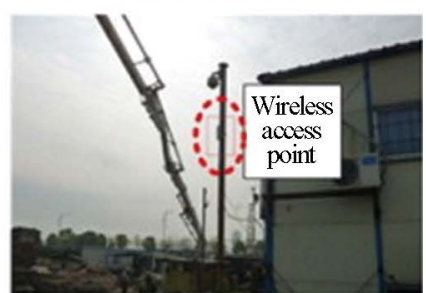

Figure 8. Architecture of IoT-based safety early warning system and transmitting devices at the construction site (Ding et al., 2013).
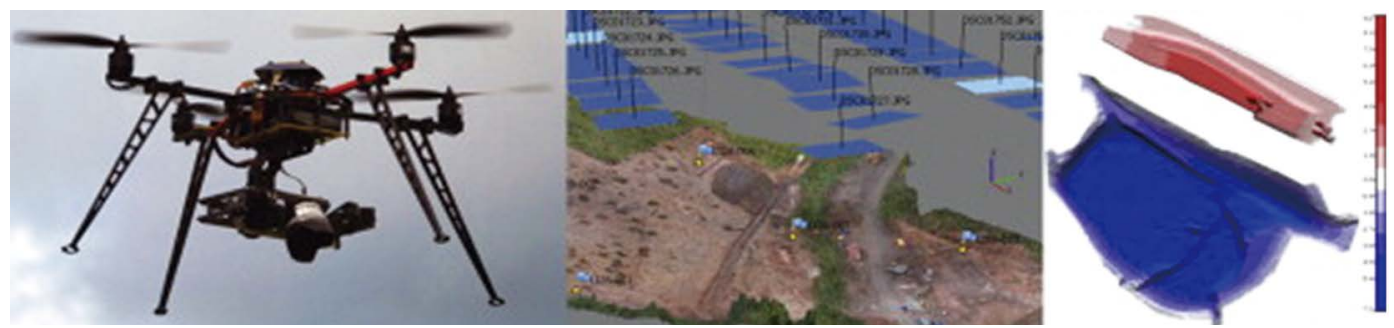

Figure 9. An Unmanned Aerial Vehicle (UAV) for mobile and autonomous acquisition of for 3D mapping of built infrastructure (Siebert \& Teizer, 2014). 


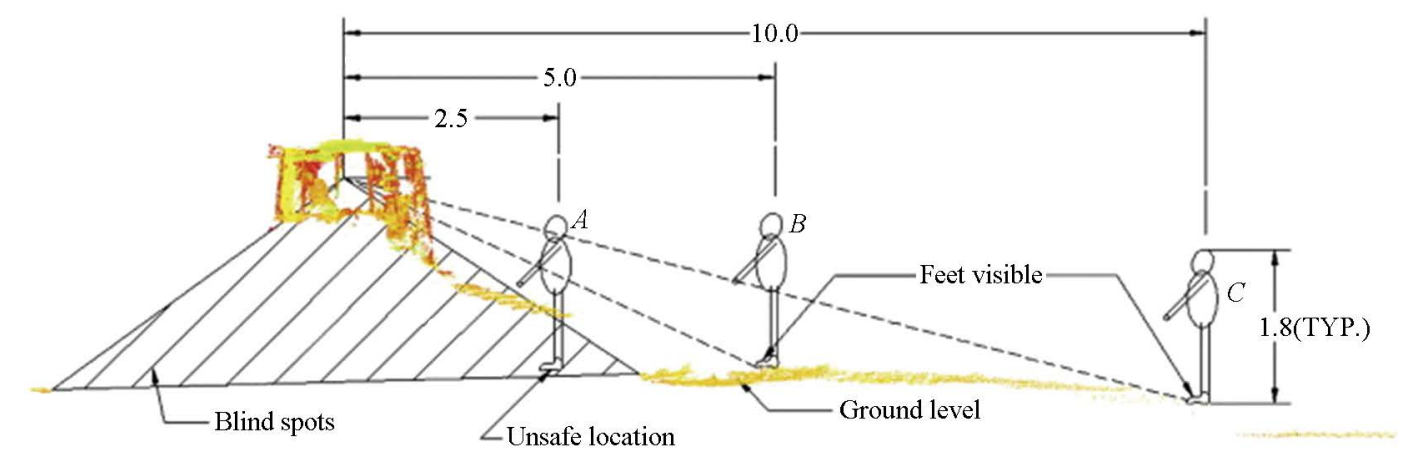

Figure 10. A worker's visibility at different locations $(A, B$, and $C)$ close to equipment (Teizer, Allread \& Mantripragada, 2010). Note: Dimensions are in meters $(\mathrm{m})$

mation acquisition. However, the accuracy and timeliness for automated recognition and retrieval of 3D BIM components from point clouds for dynamic construction process and object modeling remain to be studied further.

As demonstrated in Section 4, sensor -based systems, robotics and manipulators, and other IT-based systems are the three main research topics of the past decade in the realm of IT-based construction safety management. These technology-related aspects are closely connected to one another for achieving safe construction tasks, particularly with sensory data-saturated networks of on-site equipment.

The compilation conducted based on AUTCON articles indicates that the leading research institutions contributing most of the last decade's research on IT-based construction safety performance solutions were Georgia Institute of Technology (Georgia Tech) and Huazhong University of Science \& Technology (HUST). Researchers led by Dr. Jochen Teizer based formerly at Georgia Tech focused on real-time resource location tracking based on mobile laser scanning, automated three-dimensional as-built modeling, advanced safety for heavy equipment operation and work sites, virtual decision making environments, and safety performance learning tools. Professor Lieyun Ding based at HUST dedicated his team's activities to leading-edge research on safety risk identification and risk containment in metro construction projects. Researchers on Professor Ding's HUST team developed a metro construction safety control system and conducted pioneering research in the field of lifecycle dynamic safety control.

\subsection{Current and future research}

The use of BIM-based mobile applications will bring more interoperability and flexibility to field construction management. The combination of BIM and GIS technologies will create more location-based applications with the potential to integrate multiple BIM-based projects on a larger scale such as a city subdivision, municipal administrative units, and at even higher levels of jurisdiction. Also, precise indoor object recognition will help establish the corresponding relationship between as-build components and BIM elements for construction safety compliance verification.

A look at the on-going research awarded by U.S. and China's National Science Foundation (NSF) provides a perspective on government policy on science and technology in regard to IT-based construction management. More details are likely to become available upon the completion of the ongoing research in the U.S. and China as the corresponding authors from these two countries have historically contributed most of the articles in AUTCON on this particular topic.

In the last three years, there have been four new U.S. NSF-funded research projects related to construction safety: (1) AIR Option 1: Technology Translation: Development and Evaluation of Field Prototype for Determining Excavator Proximity to Buried Utilities (University of Michigan, 2013); (2) GOALI: Geo-referenced Visualization and Emulated Proximity Monitoring for Real Time Knowledge-Based Excavator Control (University of Michigan Ann Arbor, 2012); (3) Collaborative Research: Correlating Geospatial Data Lineage and Positional Accuracy for Excavation Damage Prevention (Purdue University, 2013); (4) Collaborative Research: Automatic Behavior Monitoring for In-depth Analysis of Construction Fatalities and Injuries (University of Michigan Ann Arbor, 2012).

In the last three years, China's National Science Foundation has supported the following seven construction safety projects: (1) Research on organization network model and case study of civil engineering construction safety knowledge sharing (HUST, 2014); (2) Behaviors Simulation model and its application based on system dynamics modeling and multi-agent modeling related to civil engineering construction safety (Tsinghua University, 2014); (3) Study on the mechanism of unsafe behavior of construction workers and their application in construction safety management (Tsinghua University, 2013); (4) Construction safety control theory and method of metro adjacent bridge (Beijing Jiaotong University, 2014); (5) Study on the tunnel construction safety and control mechanism of blasting in confined space (Beijing Jiaotong University, 2013); (6) Metro safety monitoring data reconstruction and construction safety risk assessment based on Compressed sensing (HUST, 2013); (7) Study on impact of stakeholders behavior on construction safety mechanism 
and organizational behavior modification (China University of Mining \& Technology, 2011); (8) Research on real time early warning safety control of metro tunnel deformation based on uncertainty theory and Bayesian network (HUST, 2014).

Nearly half of the ongoing research focuses on underground construction safety management due to the massive volume of metro construction activities in China and their associated safety issues. Much of this effort has been reported in recent issues of AUTCON but not explicitly reviewed in this paper (Chu et al., 2013; Dzeng, Fang \& Chen, 2014; Jung, Chu \& Hong, 2013; Lee, C. \& Lee, G., 2014; Teizer, Cheng, Fang, 2013; Zhang \& Fang, 2013). The complexity and uncertainty of large-scale metro construction brings more technical and managerial challenges such as adjacent building foundation protection, severe geological conditions, tight construction schedules, newly applied innovative construction methods create excellent new opportunities for current and future construction safety engineering and related IT research.

Acknowledgements The author appreciates the comprehensive assistance of Miss Lijuan Chen, a visiting scholar at the University of Maryland e-Construction Group, with data gathering and compilation that led to the drafting of this article.

\section{References}

Abderrahim, M., et al. (2005). A mechatronics security system for the construction site. Automation in Construction, 14(4), 460-466.

Bosche, F., \& Haas, C.T. (2008). Automated retrieval of 3D CAD model objects in construction range images. Automation in Construction, 17(4), 499-512.

Carbonari, A., Giretti, A., \& Naticchia, B. (2011). A proactive system for real-time safety management in construction sites. Automation in Construction, 20(6), 686-698.

Chae, S., \& Yoshida, T. (2010). Application of RFID technology to prevention of collision accident with heavy equipment. Automation in Construction, 19(3), 368-374.

Cheng, T., et al. (2011). Performance evaluation of ultra wideband technology for construction resource location tracking in harsh environments. Automation in Construction, 20(8),1173-1184.

Cheng, T., \& Teizer, J. (2014). Modeling tower crane operator visibility to minimize the risk of limited situational awareness. Journal of Computing in Civil Engineering, 28(3).

Chu, B., et al. (2013). Robot-based construction automation: An application to steel beam assembly (Part I). Automation in Construction, 32, 46-61.

Cinkelj, J., et al. (2010). Closed-loop control of hydraulic telescopic handler. Automation in Construction, 19(7), 954-963.

Costin, A., Pradhananga, N., \& Teizer, J. (2012). Leveraging passive RFID technology for construction resource field mobility and status monitoring in a high-rise renovation project. Automation in Construction, 24, 1-15.

Ding, L. Y., et al. (2013). Real-time safety early warning system for cross passage construction in Yangtze Riverbed Metro Tunnel based on the internet of things. Automation in Construction, 36, $25-37$.

Ding, L. Y., \& Li, H. (2013). Information technologies in safety management of large-scale infrastructure projects. Automation in Construction, 34, 1-2.

Ding, L. Y., et al. (2012). Safety risk identification system for metro construction on the basis of construction drawings. Automation in Construction, 27, 120-137.

Ding, L. Y., \& Zhou, C. (2013). Development of web-based system for safety risk early warning in urban metro construction. Automation in Construction, 34, 45-55.

Dolinsek, B., \& Duhovnik, J. (1998). Robotic assembly of rebar cages for beams and columns. Automation in Construction, 8(2), 195207.

Du, J. C., \& Teng, H. C. (2007). 3D laser scanning and GPS technology for landslide earthwork volume estimation. Automation in Construction, 16(5), 657-663.

Dzeng, R. J., Fang, Y. C., \& Chen, I. C. (2014). A feasibility study of using smartphone built-in accelerometers to detect fall portents. Automation in Construction, 38(0), 74-86.

Golparvar-Fard, M., et al. (2011). Evaluation of image-based modeling and laser scanning accuracy for emerging automated performance monitoring techniques. Automation in Construction, 20(8), $1143-1155$.

Han, C. S., et al. (2006). A multidegree-of-freedom manipulator for curtain-wall installation. Journal of Field Robotics, 23(5), 347360 .

Hussien, B., \& McLaren, R. W. (1992). Obstacle avoidance in path planning using intersection constraint search. Automation in Construction, 1(3), 285-295.

Hussien, B., \& McLaren, R. W. (1993). Real-time robot path planning using the potential function method. Automation in Construction, 2(3), 241-250.

Hu, Z. Z., \& Zhang, J. P. (2011). BIM- and 4D-based integrated solution of analysis and management for conflicts and structural safety problems during construction: 2. Development and site trials. Automation in Construction, 20(2), 167-180.

Hwang, S. (2012). Ultra-wide band technology experiments for real-time prevention of tower crane collisions. Automation in Construction, 22, 545-553.

Jung, K., Chu,B., \&Hong, D. (2013).Robot-based construction automation: An application to steel beam assembly (Part II). Automation in Construction, 32, 62-79.

Jung, K., et al. (2013). An implementation of a teleoperation system for robotic beam assembly in construction. International Journal of Precision Engineering and Manufacturing, 14(3), 351-358.

Kamardeen, I. (2013). OHS Electronic Management Systems for Construction, Taylor and Francis: Hoboken.

Kelm, A., et al. (2013). Mobile passive Radio Frequency Identification (RFID) portal for automated and rapid control of Personal Protective Equipment (PPE) on construction sites.Automation in Construction, 36, 38-52.

Kim, Y. S., et al. (2009). A performance evaluation of a Stewart platform based Hume concrete pipe manipulator. Automation in Construction, 18(5), 665-676.

Kim, K. T., \& Elernold, L. E. (2008). A comparison of two innovative technologies for safe pipe installation - "Pipeman" and the Stewart-Gough platform-based pipe manipulator. Automation in Con- 
struction, 17(3), 322-332.

Kim, S. K., Seo, J., \& Russell, J. S. (2012). Intelligent navigation strategies for an automated earthwork system. Automation in Construction, 21, 132-147.

Kim, S. K., \& Russell, J. S. (2003). Framework for an intelligent earthwork system - Part I. System architecture. Automation in Construction, 12(1), 1-13.

Ko, C. H. (2010). RFID 3D location sensing algorithms. Automation in Construction, 19(5), 588-595.

Lee, C., et al. (2012). Analysis of field applicability of the rotation-controllable tower-crane hook block. Automation in Construction, 21, 81-88.

Lee, C., \&Lee, G. (2014).Feasibility of beam erection with a motorized hook-block. Automation in Construction, 41(0), 25-32.

Lee, G., et al. (2012). A BIM- and sensor-based tower crane navigation system for blind lifts. Automation in Construction, 26, 1-10.

Lee, G., et al. (2009). A laser-technology-based lifting-path tracking system for a robotic tower crane. Automation in Construction, $18(7), 865-874$.

Lee, U. K., et al. (2009). Development of a mobile safety monitoring system for construction sites. Automation in Construction, 18(3), 258-264.

Li, Y. M., \& Liu, C. L. (2012). Integrating field data and 3D simulation for tower crane activity monitoring and alarming. Automation in Construction, 27, 111-119.

Lu, W., Huang, G. Q., \& Li, H. (2011). Scenarios for applying RFID technology in construction project management. Automation in Construction, 20(2), 101-106.

Maalek, R., \& Sadeghpour, F. (2013). Accuracy assessment of U1tra-Wide Band technology in tracking static resources in indoor construction scenarios. Automation in Construction, 30, 170-183.

Ma, L., Luo, B. H., \& Chen, H. R. (2013). Safety risk analysis based on a geotechnical instrumentation data warehouse in metro tunnel project. Automation in Construction, 34, 75-84.

Moon, H., et al. (2014). Development of a schedule-workspace interference management system simultaneously considering the overlap level of parallel schedules and workspaces. Automation in Construction, 39, 93-105.

Naticchia, B., Vaccarini, M., \& Carbonari, A. (2013). A monitoring system for real-time interference control on large construction sites. Automation in Construction, 29, 148-160.

Oloufa, A. A., Ikeda, M., \& Oda, H. (2003). Situational awareness of construction equipment using GPS, wireless and web technologies. Automation in Construction, 12(6), 737-748.

Park, C. S., \& Kim, H. J. (2103). A framework for construction safety management and visualization system. Automation in Construction, 33, 95-103.

Ray, S. J., \& Teizer, J. (2013). Computing 3D blind spots of construction equipment: Implementation and evaluation of an automated measurement and visualization method utilizing range point cloud data. Automation in Construction, 36, 95-107.
Saidi, K. S., et al. (2011). Static and dynamic performance evaluation of a commercially-available ultra wideband tracking system. Automation in Construction, 20(5), 519-530.

Seo, J., et al. (2011). Task planner design for an automated excavation system. Automation in Construction, 20(7), 954-966.

Siebert, S., \& Teizer, J. (2014). Mobile 3D mapping for surveying earthwork projects using an Unmanned Aerial Vehicle (UAV) system. Automation in Construction, 41(0), 1-14.

Taher, K. A. H., et al. (1994). Robotics and automation in the construction of the sliding domes of King Fahd's extension of the prophet's holy mosque in Madinah, Kingdom of Saudi Arabia. Automation in Construction, 3(1), 3-9.

Teizer, J., Cheng, T., \& Fang,Y.H. (2013). Location tracking and data visualization technology to advance construction ironworkers' education and training in safety and productivity. Automation in Construction, 35, 53-68.

Teizer, J., et al. (2010). Autonomous pro-active real-time construction worker and equipment operator proximity safety alert system. $A u$ tomation in Construction, 19(5), 630-640.

Teizer, J., Allread, B. S., \& Mantripragada, U. (2010). Automating the blind spot measurement of construction equipment. Automation in Construction, 19(4), 491-501.

$\mathrm{Wu}, \mathrm{W}$. W., et al. (2013). An integrated information management model for proactive prevention of struck-by-falling-object accidents on construction sites. Automation in Construction, 34, 67-74.

$\mathrm{Wu}, \mathrm{W}$. W., et al. (2010). Towards an autonomous real-time tracking system of near-miss accidents on construction sites. Automation in Construction, 19(2), 134-141.

Yoo, W. S., et al. (2012). Genetic algorithm-based steel erection planning model for a construction automation system. Automation in Construction, 24, 30-39.

Zhang, M. Z., \& Fang, D. P. (2013). A continuous Behavior-Based Safety strategy for persistent safety improvement in construction Industry. Automation in Construction, 34, 101-107.

Zhang, J. P., \& Hu, Z. Z. (2011). BIM- and 4D-based integrated solution of analysis and management for conflicts and structural safety problems during construction: 1. Principles and methodologies. Automation in Construction, 20(2), 155-166.

Zhang, S. J., et al. (2013). Building Information Modeling (BIM) and Safety: Automatic Safety Checking of Construction Models and Schedules. Automation in Construction, 29, 183-195.

Zhou, C., Ding, L. Y., \& He, R. (2013). PSO-based Elman neural network model for predictive control of air chamber pressure in slurry shield tunneling under Yangtze River. Automation in Construction, 36, 208-217.

Zhou, Y., Ding, L. Y., \& Chen, L. J. (2013). Application of 4D visualization technology for safety management in metro construction. Automation in Construction, 34, 2536. 